\title{
Influencing of Ring Die L/D Ratio and Pre-conditioner Operational Parameters on Pellet Mill Performance and Sinking Fish Feed Pellets Quality Kaddour, $\mathbf{O}$. \\ Engineering Sciences Department -Faculty of Fish Resources - Suez University
}

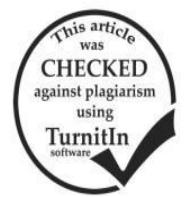

\section{ABSTRACT}

Selecting the right die to produce any kind of animal feed pellets becomes one of the difficulties is facing the pellet mill factories. Most of aquatic feed pellet mill factories use dies with holes diameter of $3.5 \mathrm{~mm}$, while the market has different dies with the same holes diameter, but with different total thickness and different L/D ratio, because the dies hole diameter of $3.5 \mathrm{~mm}$ not just use for fish feed pellets as well as for poultry feed, and rabbits feed pellets. The main experiments were carried out in one of aquatic feed Pellet mill plant to determine the optimum fish feed ring die design specifications and die holes dimensions. The parameters under investigation were three kinds of dies with different total thickness and L/D ratio, four different formula retention time in pre conditioner and three different formula temperature in pre-conditioner. The obtained results recommended the use of die 2 ( $45.5 \mathrm{~mm}$ total thickness with 1:13 L/D ratio) with die entry diameter of $4.25 \mathrm{~mm}$ without relief, and optimum pre conditioner processing were $90 \mathrm{~s}$ retention time, and $85 \mathrm{C}^{\circ}$ formula temperature, the obtained results of this parameters were $7.553 \mathrm{Mg} / \mathrm{h}$ pellet mill production rate and $7.277 \mathrm{Mg} / \mathrm{h}$ final production rate after cooling and sifting by decrease in productivity of $3.97 \%, 137$ A motor current, $9.36 \mathrm{~kW} . \mathrm{h} / \mathrm{Mg}$ energy requirement of pellet mill, $101.12 \mathrm{C}^{\circ}$ operating die temperature in the range of safe die temperature. The measured quality produced aquatic feed pellets were $903.20 \mathrm{~kg} / \mathrm{m}^{3}$ pellets bulk density, $95.69 \%$ pellets durability, and $70.67 \%$ and $33.24 \%$ pellets water stability after 30 and 60 minutes sinking in water. The study recommended use the previous mentioned die specification with any pellet mill capacity with change in die eternal diameter

Keywords: Pellet Mill- Sinking Feed Pellets- Ring Die- Die L/D Ratio- Pre-Condationer-Bulk Density- Durability- Pellets Water Stability

\section{INTRODUCTION}

Egypt is considered one of the most important countries in aquaculture, it's ranked eighth in the world aquaculture ranking, and coincided with the direction of the political leadership in Egypt for the expansion of aquaculture as one of the effective solutions to cover the shortage of customized individual from the animal protein. The aquaculture sector continues to grow as the global consumption of fish is also increasing, while global fishery catches remain stagnant or have been decreasing during the past years (FAO, 2017).With the increase in fish-cultured area and increased demand for fish feed during the season from April to November, there has been an increase in the number of plants producing fish feed .Recent trends in the fish feed industries are moving strongly towards to produce the sinking and floating cooked aquatic feed by extruder, however most of fish feed plants still use the ring die pellet mill to produce the fish feed pellets 25 and $30 \%$ protein with pellets diameter of $3.5 \mathrm{~mm}$. Pellet mill plants can be produce all the kind of feed accept the floating fish feed and pet food as expanded product. With increasing demand for fish feed, through the season it become a goal for any pellet mill plant to increase the profitability. The quality of fish feed is the standard of increasing demand for factory product, such as the protein percentage, feed conversion rate, pellet bulk density, and pellets water stability. There are two methods of feed granulating, pelleting and extrusion processing. Pelleting process use a simple technology than extrusion with lower energy requirements, and low processing cost, but in same time the feed produced by pelleting process has low water stability and high losses (Rout and Bandyopadhyay 1999, NRC 2011, and Kamarudin et al., 2018).Producing high quality of feed pellets depends on physical parameters such as raw material particle size distribution, moisture content and a homogeneously and mechanical parameters such as die thickness and die holes diameters(Mani et al. 2006).The standardized of pellets quality with the effect on handling and storage were determined as; pellets bulk density, pellets durability, and fines losses percentage after pelleting. The bulk density should be high to ensure the handling efficiency and increase the pellets stability. The pellets durability is important as indicate in pellets bulk cargo transported or when use the screw conveyor to move the pellets to storage tanks (Thek and Obernberger 2004).

Pellets bulk density and durability are the most important measurements that determine the quality of feed, many variables affecting the pellets density and durability, physical variables, such as moisture content, particle size, and formulations, and pellet mill process variables, such as die speed, die LID ratio, die holes diameter, die temperature, and steam conditioning process(Tumuluru , 2016).

Durability measurement showed the solidity of the pellets during storage, handling and transportation. In addition, it can be indicated to the ability of the pellets for, impact, and friction resistances during handling, storage, and transportation process. Higher pellet durability is desirable as it helps the pellets to retain size and shape without any breakage or cracking during and after this process (Tumuluru et al., 2010).Also the die temperature affecting the pellets bulk density and durability that what (Magnus et al., 2017b) found under stable production conditions were maintained, at die temperatures of $80 \mathrm{C}$, the durability values above $83 \%$, but bulk density decreased from 683 to $601 \mathrm{~kg} / \mathrm{m}^{3}$ by cooling the die by water injection rate was increased from 18 to $58 \mathrm{Ll}$ $\mathrm{h}$. It is certain that the die L/D ratio (effective thickness / die holes diameter) greatly affects the pellets bulk density and durability so on the pellets water stability. Raw material as physical factors such as (material type, particle size, moisture content, etc.), and mechanical factors such as (die temperature, and compression force) are responses such as pellet density, pellet strength, and friction force .The above mentioned responses are indirect measures of pellet bulk density, pellet durability, and pelletizing energy consumption. (Larsson, and Rudolfsson 2012).

Also Larsson et al (2012) said that in regular ring die pellet mill, die temperature and compression force cannot be controlled but are indicate with material properties such as moisture content and pelleting process such as die channel length and that affecting the die temperature and motor current .Data showed the die holes press channel dimensions of $52.5 \mathrm{~mm}$ press length and $8 \mathrm{~mm}$ die holes diameter, resulting in a performance ratio (L/D ratio) of 6.5:1resulting steady pelleting performance, while increasing the L/D ratio lead to increase the die temperature conditioning of formula one of the most important process in pellet mill production, It 
depends on the exposure the feed formulation to the dry steam with stirring inside the pellet mill pre-conditioner until the granules absorb the steam, which helps in the compression processes inside the die, reduce the energy consumption, and increase the pellet mill productivity. The time consumed which the feed formulation takes inside the pellet mill pre- conditioner called conditioning retention time. Tumuluru (2015) reported that steam conditioning of bio mass helps to activate the binding of components, which assist to produce high durable pellets. Data indicated that increasing the die temperature to $110^{\circ} \mathrm{C}$ reduce the pellets buck density. Same indication by pelletizing torrefied materials by pellet mill using different press channel lengths of $(25$ and $30 \mathrm{~mm})$.The obtained results were, pellets bulk densities of 558 and $725 \mathrm{~kg} \mathrm{~m}^{-3}$ and durability's of 46.3and $86.5 \%$, respectively, (Magnus et al.2017a).On other hand the energy requirement of the pelleting process is one of the factors that animal feed producers care about it, the motor current of pellet mill indicator for the power consumed that affects greatly the energy requirement.

Reed et al. (1980) found that specific energy consumption of the pelleting process depends on pellet mill operation parameters such as die L/D ratio, die diameter, die rotating speed, and pellet mill feed rate. Tumuluru et al., (2016) reported that adding 2 and $4 \%$ of corn starch to the milled corn stover reducing the specific energy consumption about $30-40 \%$ and increased the pellets durability to $>99 \%$.Comparing the specific energy requirements of flat die pellet mill with ring die pellet mill, ring die pellet mill may be impaired by the high specific energy requirements than flat die, data showed the specific energy requirement of flat die were between101 to $324 \mathrm{kWh} / \mathrm{Mg}$ depending on formula moisture content and die holes dimensions.

Jackson et al. (2016). The aquatic feed pellets producing by ring die pellet mill in Egypt not has stander L/D) ratio, and pre-conditioner retention time and formula temperature that affecting the pellet mill performance and pellets quality, in Egypt market there are many dies holes dimensions of ring dies for same model of pellet mill and same die hole diameter, the dies manufacturing factories produced the dies according to the plant formulations or suppliers order. Most of pellet mill owners do not know what is the right die total thickness and L/D ratio and buy the dies from local companies and have a lot of troubles in plant performance such as high percentage of mash formula losses, the reduce in pellets production rate, low pellets durability and water stability. It is not just the problem that the plant facing but the common die holes size for fish feed is $3.5 \mathrm{~mm}$, and the same size is used for producing another kinds of feed pellets such as poultry and rabbits feed pellets and all of this kinds of feed has different formulations and should be has different die L/D ratio and different steam conditioning process. The aim of this research is to establish a criteria that enable the owners of fish feed factories to choose the suitable ring die that will achieve the highest performance of the pellet mill with the best aquatic feed pellets quality, and determine the optimum operating parameters of the preconditioner temperature and formula retention time.

\section{MATERIALS AND METHODS}

The pellet mill capacity is determined by the die internal diameter, the stander dies size are 250, 320, 350, 400, 420, 508 and 578 for different pellet mill capacity from 1 to $20 \mathrm{Mg} \backslash \mathrm{h}$, for example the common usually used model in Egypt is SZLH 420, which means the die internal diameter is $420 \mathrm{~mm}$ and the pellet mill capacity will be around 7 to $10 \mathrm{Mgh}$, depends on the kind of feed formulation and the die holes diameters.

The experiments were carried out in one of the fish feed factories in the fish farms area of Al-Hassania Famous city in Sharqia governorate. The pellet mill plant capacity was 7-10 Mgh, the factory was exposed to many problems in production with the change of the dies from different suppliers and problems with the production of the line and the pellets durability and pellets water stability.

Materials:

\section{The Tilapia fish feed $(25 \%$ protein) formulation composition:}

A factory standard fish feed formula for Tilapia fish with content of $25 \%$ protein were used in the experiments to evaluate the manufactured dies under investigation. The formulation composition was: Corn seeds 30\%, Soybean meal (44\% protein) $16 \%$, Wheat bran $15 \%$, Rice bran $15 \%$,Fish meal (60\% protein) $10 \%$, Corn Gluten $(60 \%$ protein) 10\%,DY Calcium Phosphate 0.5\%, Limestone 3\%, Salt $0.35 \%$, Vitamins $0.1 \%$, and Anti-toxin $0.05 \%$. The formula components were milled by fine grinding hammer mill with $90 \mathrm{~kW}$ motor and have screen holes of $1 \mathrm{~mm}$ and mixed by double shaft paddle mixer.

The pellet mill specifications and aquatic feed dies design dimensions

The fish feed factory has ring die pellet mill model SZLH420-2A with capacity from 7 to $10 \mathrm{Mg} / \mathrm{h}$, the pellet mill has double pre-conditioner to control the formula retention time mixed with steam. Generally any ring die pellet mill consists of main parts such as pellet mill feeder, pre-conditioner (single, double or triple conditioner), and die and rollers chamber and power transmission.

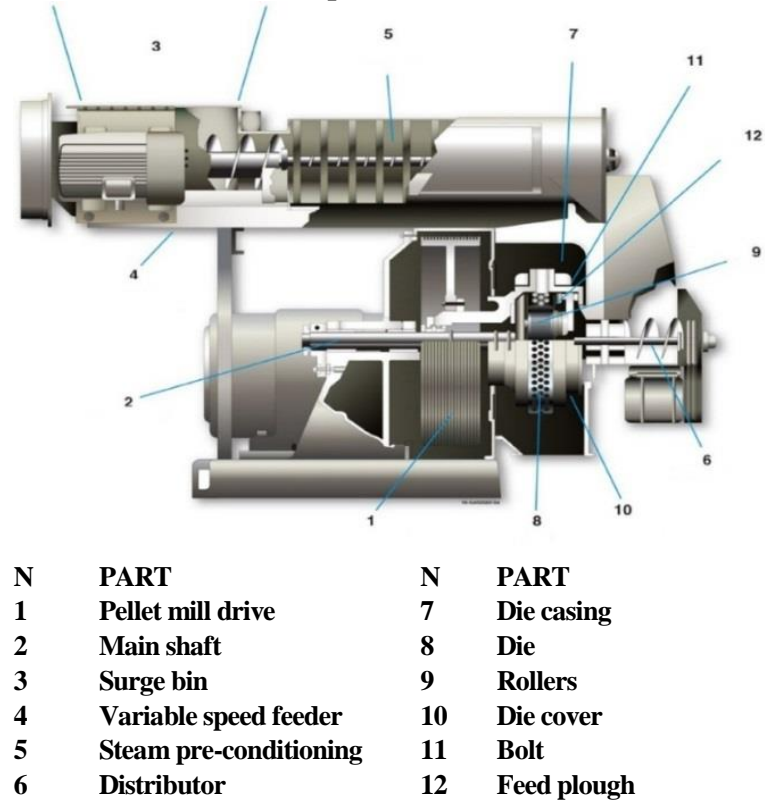

Fig. 1. Schematic of the pelleting process (FAO, 1980).

The pellet mill under studding is ring die pellet mill gear box type, model SZLH 420-A2 with average capacity of $7-10 \mathrm{Mg} / \mathrm{h}$., the pellet mill specification and dimensions were: Screw feeder:

The screw feeder consists of the feeder chamber made from stainless steel 304 , the feeding gate $700 \times 300 \mathrm{~mm}$ 
the feeding screw has $250 \mathrm{~mm} \varnothing$, and $1000 \mathrm{~mm}$ length and $80 \mathrm{~mm}$ pitch, the feeding rate can be adjustable by speed variable motor $1.5 \mathrm{~kW}$, with reducing rate $1: 11$ and screw rotating speed limit from 0-132 rpm. (Fig. 2).

\section{Conditioner}

The pellet mill conditioner chamber made from stainless steel 304 has double pass pre- conditioner each has $500 \mathrm{~mm} \varnothing$ and $2100 \mathrm{~mm}$ length, the conditioner shaft with paddle's made from stainless steel too the shaft has dimensions of $110 \mathrm{~mm} \varnothing$ and $2200 \mathrm{~mm}$ length, the conditioner chamber has inspection doors, and steam injection nozzles, each conditioner shaft has variable motor $5.5 \mathrm{~kW}$ to control the conditioning time between the limit of 10-50 s for each one (Fig. 2).

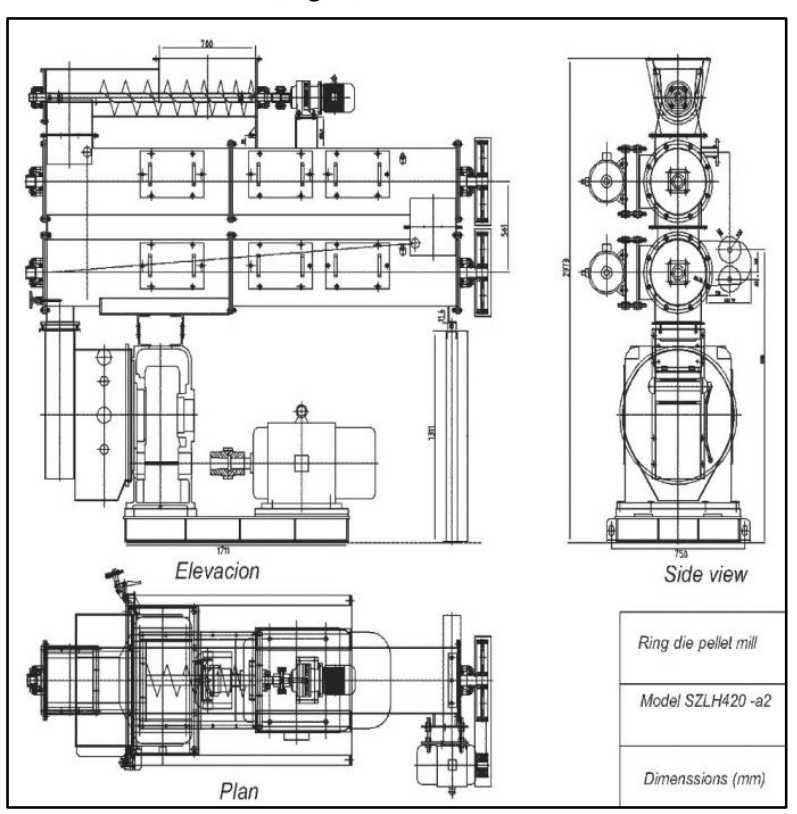

Fig. 2. Elevation, side view and plan of the ring die pellet mill

\section{Pellet mill}

The pellet mill part consists of gear box chamber and main motor, die and rollers mechanism, the pellet mill gear box is gears and pinion shaft type connected with the main motor $110 \mathrm{~kW}$, by coupling with shear pin overload Protection device to transfer the power from the motor to the die and protected the machine from any overload. (Fig. 2).

The die and rollers mechanism consists of the SZLH 420 die and the rollers set consists of two units made from alloy steel (20CrMo), each has $210 \mathrm{~mm} \emptyset, 120 \mathrm{~mm}$ width and $40 \mathrm{~mm}$ thickness, the rollers has rollers holder mechanism with 2 sets of bearings give the rollers free rotating by the die drive rotate through the formulation material between the die and rollers by the sequences of pelleting process. Fig (3).

The fish feed factories often used imported ring dies, most of factory production produced by dies has holes diameter of $3.5 \mathrm{~mm}$, Three of the common dies used in fish feed factories has different total thicknesses and different L/D ratios wereused in this study, the dies specifications and design dimensions were: die (1) total thickness of $39.5 \mathrm{~mm}$, effective length of $27.5 \mathrm{~mm}$, die holes relief of $12 \mathrm{~mm}$, die (2) total thickness of $45.5 \mathrm{~mm}$, effective length of $45.5 \mathrm{~mm}$, with no die holes relief and die(3) total thickness of $55.5 \mathrm{~mm}$, effective length of $55.5 \mathrm{~mm}$, with no die holes relief. (Fig. 4).

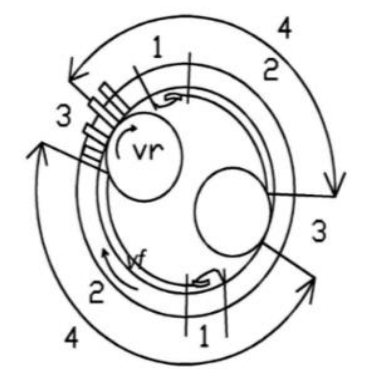

N PART

1 Zone of product intake

of product distribution Vf Circumferential die speed

3 Zone of compression $\quad \mathrm{Vr}$ Circumferential roller speed

Fig. 3. Die and rollers pelleting process sequences

The dies were made from stainless steel (40Cr13) with internal diameter $\varnothing$ of $420 \mathrm{~mm}$ and $120 \mathrm{~mm}$ track width, the die was insulatedwith the pellet mill by three pieces of clump has edges are symmetrical with die edges and flanges. The dies has cover connected with the die by 6 bolts (Figs. 5,6 ).
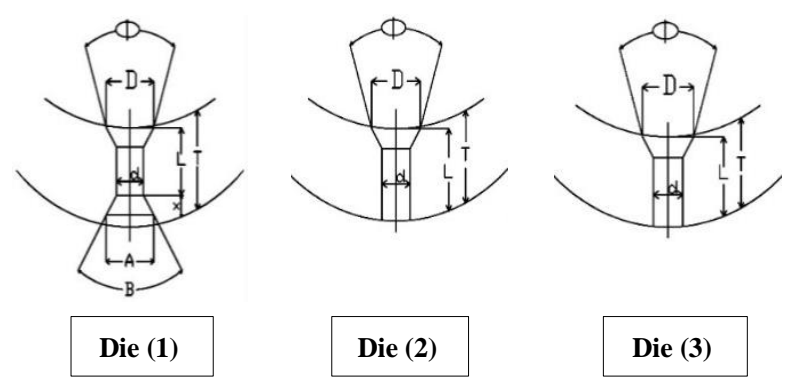

DIE DIMENSIONS

Pellet Diameter

Effective Length

Total Thickness

Die Hole Entry Diameter

Die Hole Entry Angle

Relive Depth

Relive Hole Angle

Relive Diameter

Compression Ratio

Performance Ratio

\begin{tabular}{|c|c|c|c|c|}
\hline \multirow{2}{*}{$\begin{array}{l}\text { Die (2) } \\
\text { UNIT }\end{array}$} & \multirow[b]{2}{*}{ CODE } & \multicolumn{2}{|c|}{ Die (3) } & \\
\hline & & $\begin{array}{c}\text { DIE } \\
\text { (1) }\end{array}$ & $\begin{array}{c}\text { DIE } \\
\text { (2) }\end{array}$ & $\begin{array}{c}\text { DIE } \\
\text { (3) }\end{array}$ \\
\hline$(\mathbf{m m})$ & d & 3.5 & 3.5 & 3.5 \\
\hline (mm) & $\mathbf{L}$ & 27.5 & 45.5 & 55.5 \\
\hline$(\mathbf{m m})$ & $\mathbf{T}$ & 39.5 & 45.5 & 55.5 \\
\hline$(\mathbf{m m})$ & D & 5.25 & 4.25 & 4.75 \\
\hline$\left({ }^{\circ}\right)$ & $\varnothing$ & $3.6^{\circ}$ & $3.6^{\circ}$ & $3.6^{\circ}$ \\
\hline$(\mathbf{m m})$ & $\mathbf{X}$ & 12 & 0 & $\mathbf{0}$ \\
\hline$\left({ }^{\circ}\right)$ & B & $3.6^{\circ}$ & 0 & $\mathbf{0}$ \\
\hline$(\mathbf{m m})$ & $\mathbf{A}$ & 4.25 & 0 & 0 \\
\hline (ratio) & $D^{2} \backslash d^{2}$ & 1.50 & 1.47 & 1.35 \\
\hline (ratio) & Lld & 1:7.9 & $1: 13$ & 1: 15.9 \\
\hline
\end{tabular}

Fig. 4. The aquatic feed dies holes design and dimension.
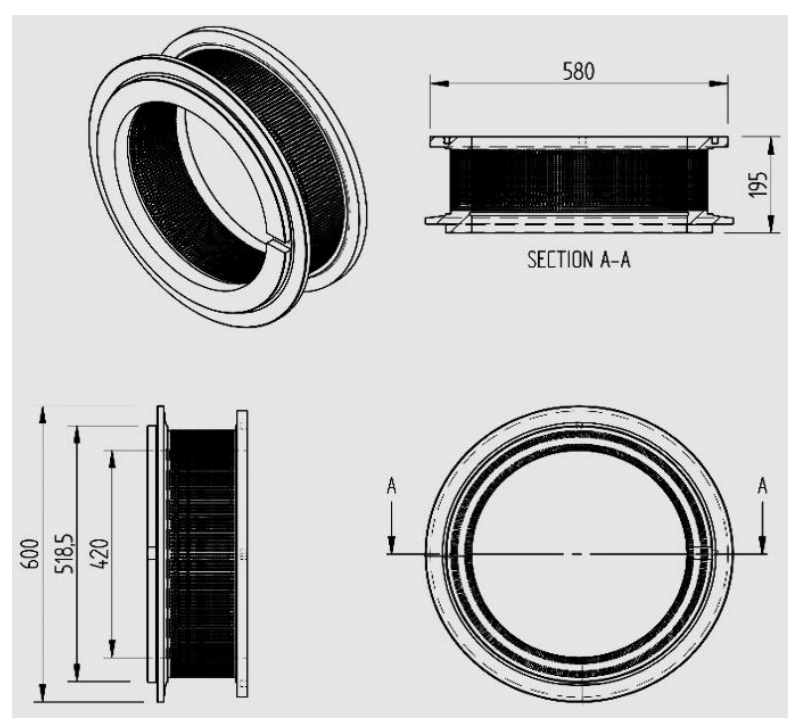

Fig. 5. Schematic of the SZLH 420 ring die 

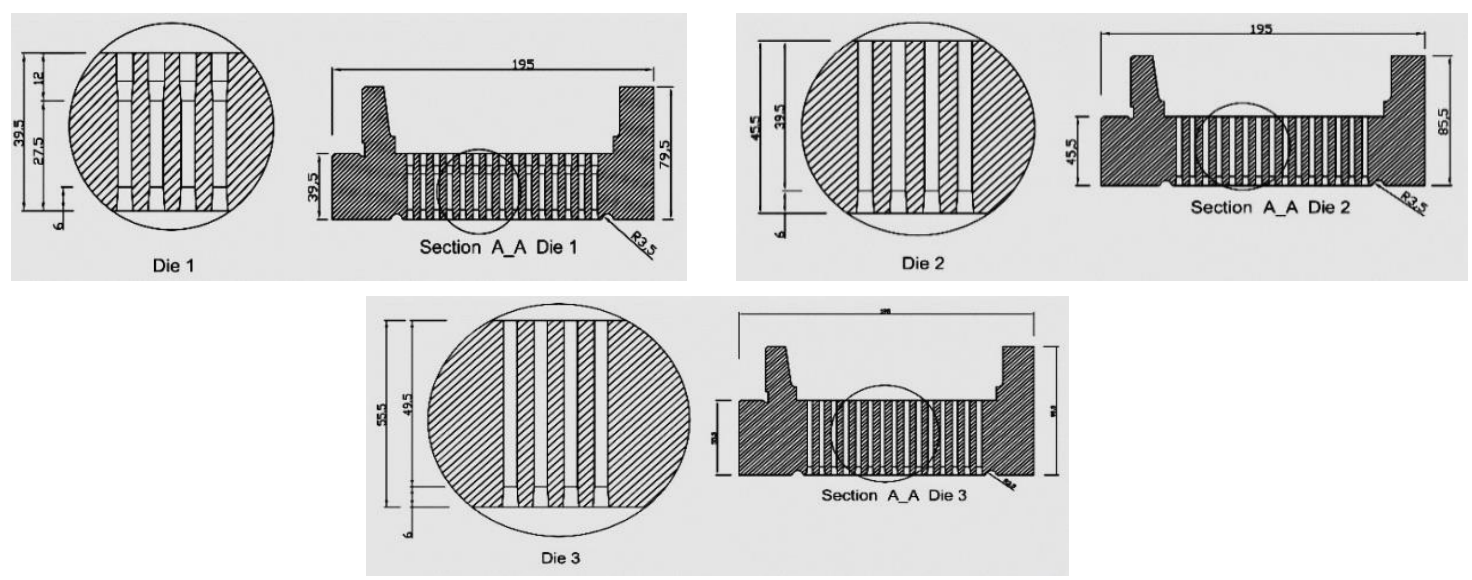

Fig. 6. Cross section (A-A) of the different aquatic feed ring dies

Methods:

\section{Experiment's conditions:}

Three of common and most used aquatic feed ring dies utilizing in fish feed pellet mill plants imported from one of dies factory in China were used to study the effect of dies total thickness, L/D ratio, formula temperature and formula retention time in the pre- conditioner on plant productivity and fish feed pellets quality. The parameters under the study and evaluation were:

- Die L/D ratio of (7.9, 13 and 15.9)

- Fish feed formula temperature in conditioner $(65,85$ and $105 \mathrm{C}^{\circ}$ )

- Formula retention time in the conditioner(70, 80, 90 and 100s)

The study constant parameters were, the three dies has same die hole diameter of $3.5 \mathrm{~mm}$, die hole entry diameter and entry angle of $4.25 \mathrm{~mm}$ and $3.6^{\circ}$ respectively, die velocity of $7.5 \mathrm{~m} / \mathrm{s}$, pellet mill feeding rate of $125 \mathrm{~kg} / \mathrm{min}$ formula moisture content after conditioner14-16\%, the steam pressure after the boiler and before pellet mill were 5.5 and 2.5 bar after steam pressure reducer, steam temperature at pellet mill valve of $125 \mathrm{C}^{\circ}$, clearance between the rollers and the die of $0.3 \mathrm{~mm}$ and all the dies were made from same alloy stainless steel (40Cr13).

Evaluation of the pellet mill ring dies performance and produced aquatic feed pellets quality:

The experiments were conducted and the different quality assessments for each ring die under unified operating conditions of automatic dosing pellet mill plant using the plant computerized control panel. The measurements and sampling was randomized from each operation and after the start of the production line by $15 \mathrm{~min}$ through three replicates to be sure the production line become steady.

\section{1-Pellet mill and packing section production rate:}

Pellet mill production rate was measured for each treatment by collecting sample for $2 \mathrm{~min}$ after line running steady. While the final production rate in packing section was measured by measuring the mass of final products after sifting in packing bins in one hour from the control panel.

2- Pellet mill motor current intensity and Energy requirements:

The pellet mill motor current intensity without load and with load was measured by the plant and pellet mill control panel, the energy requirements $(\mathrm{kW} . \mathrm{h} / \mathrm{Mg})$ were calculated by the following equations:

$$
P=\frac{\sqrt{3} I V \eta \cos \theta}{1000}
$$

Where:

$\mathbf{P}=$ Consumed power, $\mathrm{kW}$

I = Line current strength in amperes.

$\mathrm{V}=$ Potential difference (Voltage) being equal to $380 \mathrm{~V}$.

$\operatorname{Cos} \theta=$ Power factor (being equal to 0.84 ).

$\eta \quad=$ Mechanical efficiency $($ assumed $90 \%)$

$$
\text { Energy requirement }=\frac{P}{Q}=k W \cdot h / M g
$$

\section{Where:}

$\mathrm{Q}=$ Final production rate after sifting, $\mathrm{Mg} / \mathrm{h}$.

3- Die operation temperature:

The die operation temperature were measured at full capacity of pellet mill by leaser temperature device after 15 min from pellet mill start up with full load capacity.

\section{4- Aquatic feed pellets bulk density:}

Was calculated using standard method of feed manufacture, AACC, American Feed Industry Association, Inc., (2000).

\section{5- Aquatic feed pellet durability:}

Bulk density and durability of dried pellets was determined based on ASABE Standard S269.4 (2007) by 3 replicates (mass of each one was $500 \mathrm{~g}$ ) using durability turning box for $10 \mathrm{~min}$. The durability turning box consists of four cells

rotated at a

constant speed

$$
\operatorname{Durability}(\%)=\frac{W a}{W b} \times 100
$$
of $60 \mathrm{rpm}$.

\section{Where: Wa : pellets mass after treatment (g), $\mathrm{Wb}$ : pellets mass before treatment $(\mathrm{g})$}

\section{Pellets water stability:}

Was calculated by put the pellet in glass water and measuring the number of pellet still stable in water after (30, and $60 \mathrm{~min}$ ) using formula:

\section{Pellet water stability $=$ Nst $/$ Nt $\times 100$}

Where: Nst: Number of stable pellets in the water $\mathrm{N}_{\mathrm{t}}$ : Total pellets sample.

AACC, American Feed Industry Association, Inc., (2000).6- Aquatic feed

\section{RESULTS AND DISCUSSION}

\section{1-Pellet mill and packing section production rate:}

In any feed mill plant pellet mill, productivity not the true final production rate of the plant that is because the produced pellets from pellet mill has high percentage of moisture and including mash formula percentage, the powder percentage depends on the pellet mill efficiency, conditioning operations, and die hole dimensions. The actual 
production rate should be after cooling and sifting process in packing section bins

It's very important for any feed mill to measure the production rate of pellet mill and compare it with the production rate in packing section to determine the losses percentage .Data in Fig (7) indicated that changing the formula temperature from 65 to 85 and $105 \mathrm{C}^{\mathrm{O}}$ increased the pellet mill production rate as average by 1.34 and $1.53 \%$ using different dies $\mathrm{L} / \mathrm{D}$ ratios and different formula retention times in pre conditioner. While, increasing the formula retention time in pre- conditioner from 70 to 80,90 and $100 \mathrm{~s}$, reduce the production rate of pellet mill as average by 3.43 , 2.71 and $2.92 \%$ with all dies L/D ratios and formula temperatures. On another hand, changing the dies L/D ratio from 7.9 to 13 and 15.9 sharply decrease the pellet mill production rate as average with all formula retention times and temperatures by 9.73 and $16.23 \%$ recpictively.

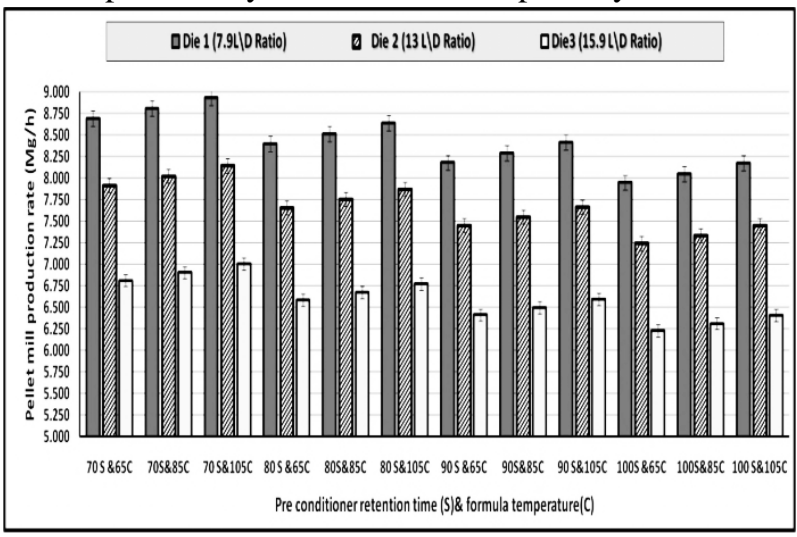

Fig. 7. The effect of die L/D ratio, formula retention time in pre-conditioner and formula temperature on pellet mill production rate

It is known that there is a significant difference between pellet mill productivity and final production rate after cooling and sifting processes, which will certainly be higher than the actual production rate since the pellet mill pellets production is accompanied by a percentage of powder (mash formula) as well as the pellets has high moisture content. Data in Fig (8) showed the effect of different parameters on packing section production rate. Results showed that changing the formula temperature from 65 to 85 and $105 \mathrm{C}^{\mathrm{O}}$ increased the pellet mill production rate as average by 1.37 and $1.51 \%$ using different dies L/D ratios and different formula retention time in pre conditioner. Meanwhile, increasing the formula retention time in preconditioner from 70 to 80,90 and $100 \mathrm{~s}$, reduce the production rate of pellet mill as average by3.48, 0.98 and $1.42 \%$ with all Dies L/D ratios and formula temperatures. Regarding to change the dies L/D ratio from 7.9 to 13 and 15.9 resulting sharply decrease in the pellet mill production rate as average with all formula retention times and temperatures by 7.69 and $8.59 \%$, respectively.

The little increase in production rate by increasing the formula temperature from 65 to 85 and $105 \mathrm{C}^{\mathrm{O}}$ could be due to the increase in formula oil viscosity that make it flow through the die holes easily. The decrease in pellet mill production rate by increasing the formula retention time from 70 to 80,90 and $100 \mathrm{~s}$ could be due to the increase in mass of formula consumed time pellet mill process. The sharply decrease in pellet mill production rate by increasing the die $\mathrm{L} / \mathrm{D}$ ratio from 7.9 to 13 and 15.9 could be due to the increase in die holes effective length and the fraction between the formula and die material that lead to increase formula holding time in die holes and reduce the pellet mass in time unit.

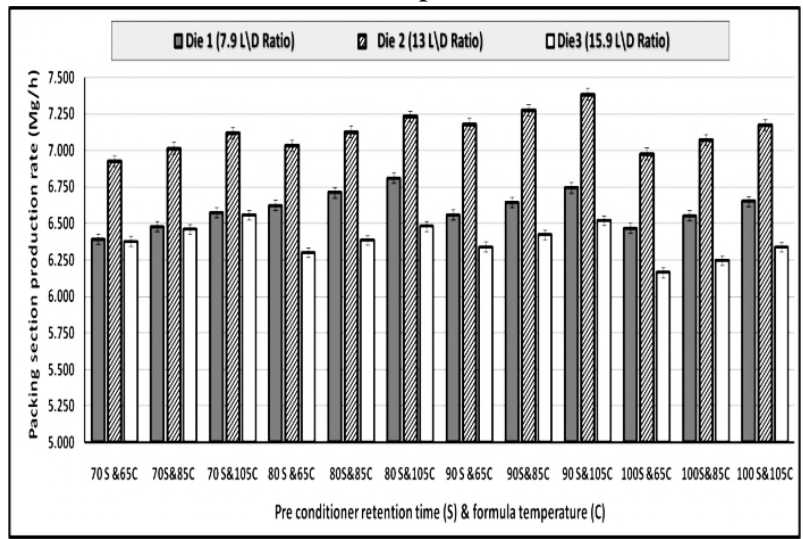

Fig. 8. The effect of die $L / D$ ratio, formula retention time in pre-conditioner and formula temperature on packing section production rate

From the previous results it is clear that the estimation of the appropriate die production through the pellet mill production rate is incorrect, but the productivity should be estimated after the cooling and sifting processes. Data in Fig (9) showed that the reduce in production rate percentage from the pellet mill production and packing section production, the decrease in production rate after cooling and sifting were $35.92,14.34$ and $6.83 \%$ at conditioning retention time of $70 \mathrm{~S}$, were $26.84,8.83$ and $4.53 \%$ at conditioning retention time of 80 s, were $24.70,3.79$ and $1.16 \%$ at conditioning retention time of $90 \mathrm{~s}$ and $22.87,3.79$ and $1.10 \%$ at conditioning retention time of 100s , using dies L/D ratios of $7.9,13$ and 15.9 respectively. There is no significant effect of formula temperature in the pellet mill pre-conditioner on the final production rate in packing section after cooling and sifting.

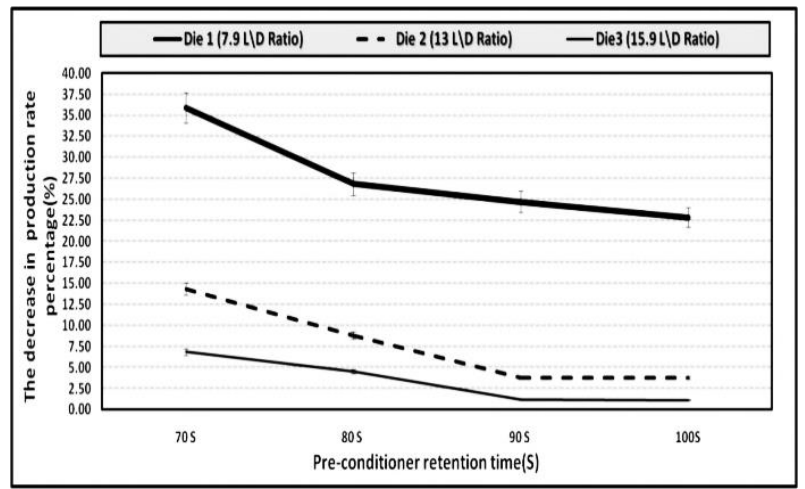

Fig. 9. The effect of die L/D ratio, formula retention time on the decrease of production rate percentage after cooling and sifting

The tangible decrease in final production rate after sifting comparing with the pellet mill production by increasing the pre conditioner retention time from 70 to 80 and 90 s, could be due to that the short retention time lead to low homogeneity between the formulation with the steam and decrease of formula absorption by steam, so increase the mash percentage with pellet mill pellets production, the mash is separated from the final pellet by the sifter. Meanwhile, no significant decrease in final production rate by increasing the retention time from 90 to 100 s the reason of this result were no tangible of formula absorption by steam.

On the other side, the sharp decline in final production rate after sifting by using die L/D ratio of 7.9 other 
than what the results showed in measuring pellet mill production rate, that could be due to the low $\mathrm{L} / \mathrm{D}$ ratio means decline in die total thickness and effective length, so lead to decrease the die holding time and increase in die output but in same time increase in mash percentage and producing fragile pellets that leads to decrease in final production rate after sifting. While using die with L/D ratio of 13 and 15.9 reduce the mash percentage after cooling and sifting by increasing the die holding time and increase the formula compact in the die effective length.

\section{2-Pellet mill motor current and specific energy}

At first glance, it is thought that the current intensity of the pellet mill motor expresses the specific energy requirement to produce the mass unit of pellets, but that is not true for all the cases, in pellet mill machine the specific energy requirement cannot be calculated according to the pellet mill production rate but according to the final production rate. So measuring the motor current is important too to know the motor load by using different dies L/D ratio. Data in Fig (10) showed the effect of Die L/D ratio and preconditioner parameters on pellet mill mean motor current, it's indicated that increasing die L/D ratio from 7.9 to 13 and 15.9 increased the pellet mill main motor current as average with all of conditioner retention times and formula temperatures by 3.67 and $10.68 \%$ respectively. The increase in motor current by increasing the L/D ratio could be due to the increase in die total thickness that requires an increase in compression force to ensure that the feed formulation flows through the holes and overcome friction resistance and the increase in holes holding time.

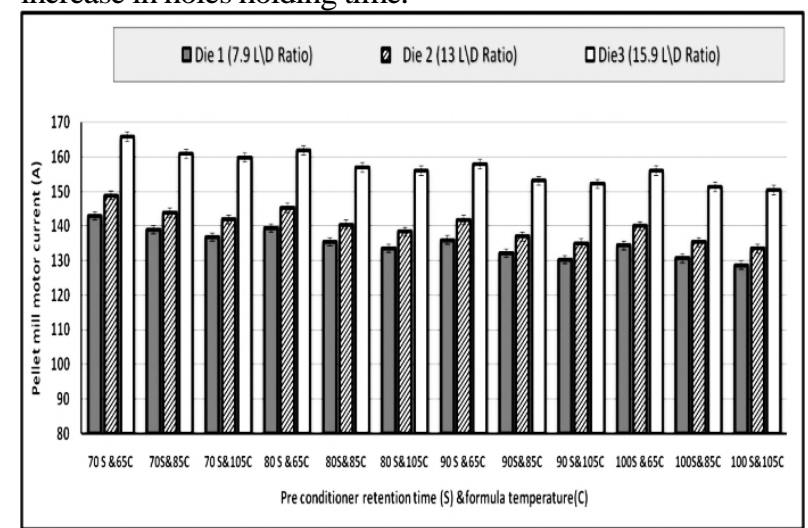

Fig. 10. The effect of die $\mathrm{L} / \mathrm{D}$ ratio, formula retention time in pre-conditioner and formula temperature on pellet mill motor current

While increasing the formula retention time in preconditioner from 70 to 80,90 and 100 s decreased slightly the motor current as average at all formula temperatures and dies L/D ratios by $2.41,2.49$ and $2.53 \%$ respectively. This decrease in motor current attributed to the increase in formula retention time provides the opportunity for the formula to be saturated with steam, which facilitates the flow inside the die holes and reduce the friction force. Same effect results in Fig (10) showed that increasing the formula temperature in pre-conditioner from 65 to 85 and 105 Co results an intangible decrease in pellet mill motor current at all the dies L/D ratio and pre-conditioner retention time by 1.35 and 1.35 and $1.51 \%$ respectively. The decrease in motor current by increasing formula temperature could be due to increase in temperature lead to reduce the formulation fish oil viscosity that increase the formula flow rate in dies holes, reduce the formula holding time and decrease the resistance and the motor load.
Regarding to the pellet mill specific energy requirements (SE), data in Fig (11) showed the effect of different pellet mill operation parameters on energy requirements, results indicated that the dies total thickness and L/D ratio are the most important factors affecting the pellet mill specific energy requirements, increasing the die L/D ratio from 7.9 to 13 reduce the specific energy(SE) requirements of pellet mill as average at all the formula temperatures and preconditioner retention times by $4.01 \%$.The decrease in(SE) by increasing the die L/D ratio from 7.9 to 13 Is attributed to high increase in final production rate after sifting with little increase in power consumed and motor current of pellet mill. While increasing the die L/D ratio from 13 to 15.9 increase the energy requirements of pellet mill as average at all the formula temperatures and pre-conditioner retention times by $20.0 \%$. The increase in (SE) by increasing the die L/D ratio from 13 to 15.9 could be due to the high decrease in final production rate after sifting with high increase in power consumed and motor current of pellet mill.

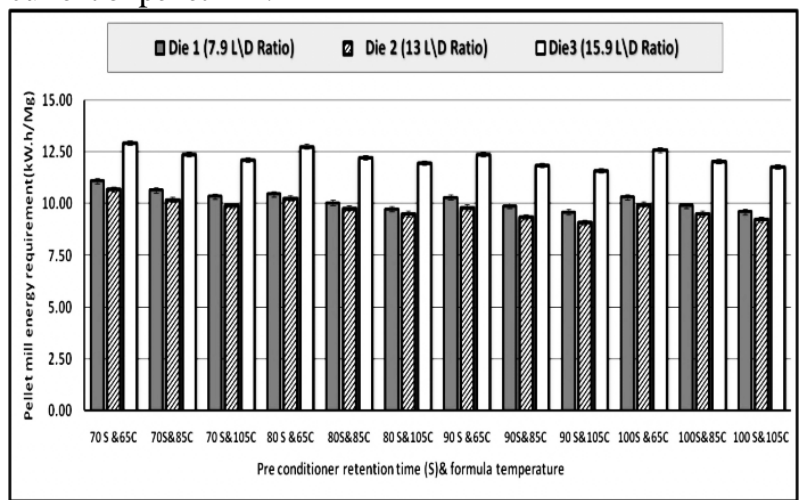

Fig. 11. The effect of die $L / D$ ratio, formula retention time in pre-conditioner and formula temperature on pellet mill specific energy requirements.

Also same Fig (11) showed that increasing the pre conditioner retention time from 70 to 80,90 and 100 s , using dies L/D ratio of 7.9 and 13 ,decreased the (SE) as average for all formula temperatures by 3.84, 4.37 and $2.19 \%$ respectively. The decrease in (SE) by increasing the pre conditioner retention time using dies L/D ratio of 7.9 and 13 could be due to the increase in final production rate. Meanwhile increase the pre conditioner retention time from 70 to 80,90 and 100 s using die L/D ratio of 15.9 increased the (SE) as average for all formula temperatures by $0.19,1.67$ and $1.61 \%$ respectively. The increase in (SE) by increasing pre conditioner retention time using die L/D ratio of 15.9 could be due to the high decrease in final production rate with low decrease in pellet mill power consumed. Data in Fig (11) indicated that too the effect of formula temperature in preconditioner on the (SE), increasing the formula temperature in pre-conditioner from 65 to 85 and $105 \mathrm{Co}$ decreased the (SE) as average using all dies L/D ratios and pre conditioner retention time by 1.63 and $1.71 \%$ respectively. The little decrease in (SE) by increasing the formula temperature in pre-conditioner from 65 to 85 and 105 Co could be due to the slight increase in final pellets production with decrease in pellet mill power consumption.

\section{3- Die operation temperature}

Die running temperature is one of the most important measurement in any pellet mill plant, the dies operating temperature should be measured to ensure that it does not exceed permissible limits, the high increase in die temperature 
actually lead to damage the rollers bearings, causing blockage in the die holes as a result of formula burning and change in produced pellets standard specifications. Data in Fig (12) showed that increasing the die L/D ratio from 7.9 to 13 and 15.9 increased the die temperature as average at all the formula temperatures and pre-conditioner retention times from 80.94 to 100.92 and $125.26 \mathrm{Co}$ respectively. The increase in die temperature by increasing the die $\mathrm{L} / \mathrm{D}$ ratio could be due to the increase in die effective length and that lead to increase the fraction between the die holes material and formula with the increasing in die holding time.

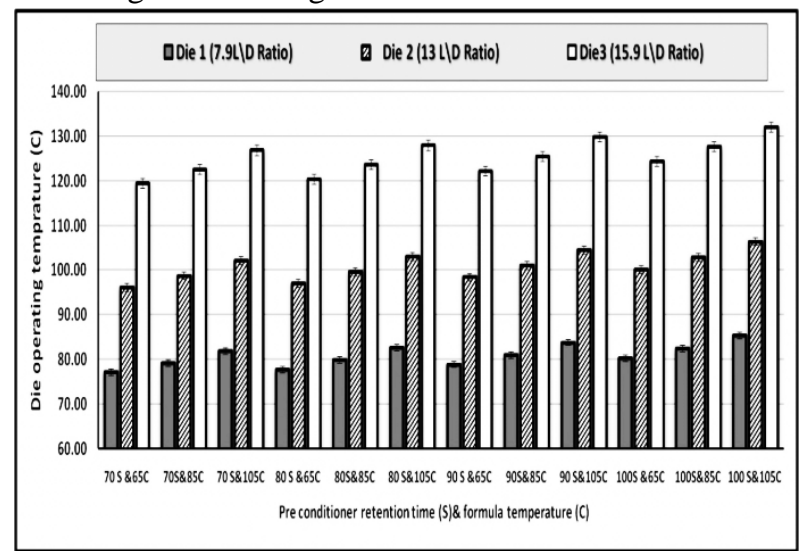

Fig. 12. The effect of die L/D ratio, formula retention time in pre-conditioner and formula temperature on die operation temperature

From previous data in Fig (12) it is indicated that increasing formula retention time in pre-conditioner increased the die operating temperature through positive relation, data showed that increasing formula retention time in preconditioner from 70 to 100 s increased the die operating temperature as average for all formula temperatures from 79.48, 99.11 and $123.01 \mathrm{C}^{\mathrm{o}}$ to $82.77,103.21$ and $128.10 \mathrm{C}^{\circ}$ using dies L/D ratio of 7.9, 13 and 15.9 respectively. Same indication for formula temperature in pre-conditioner showed in Fig (12), increasing the formula temperature from 65 to $105 \mathrm{C}^{\mathrm{o}}$ as average at all formula retention times from 78.60, 98.01 and $121.64 \mathrm{C}^{\circ}$ to $83.50,104.11$ and $129.22 \mathrm{C}^{\circ}$ using dies L/D ratio of 7.9, 13 and 15.9 respectively. The increase in die temperature by increasing the formula retention time and formula temperature could be due to increase the of the formula exposure time to the steam injection in the pre conditioner, which raises the formula temperature and that lead to trivial increase in die temperature.

\section{4- Aquatic feed pellets bulk density}

Pellets bulk density is considered one of the major quality control measurement in any pellet mill factory, Data in Fig (13) showed that increasing the die L/D ratio from 7.9 to 13 and 15.9 increased the pellet bulk density as average at all formula retention times and formula temperatures by 7.90 and $4.60 \%$ respectively.

The increase in pellets bulk density by increasing the L/D ratio could be due to the increase in die total thickness and effective length, increase the holding time, and that lead to increase formula granules compact with decrease the interfaces between the granules, all that resulted increase the pellets mass in constant volume.

While data showed that increasing formula retention time in pre-conditioner from 70 to 80,90 and 100 s increased the pellets bulk density as average for all L/D ratios and formula temperatures by1.33, 1.92 and $2.51 \%$ respectively.
Regarding to the effect of formula temperature on pellets bulk density same figure showed that increasing formula temperature from 65 to 85 and $105 \mathrm{C}^{\mathrm{o}}$ increased the pellets bulk density as average for all L/D ratios and formula retention times in pre-conditioner by 1.84 and $1.72 \%$ respectively.

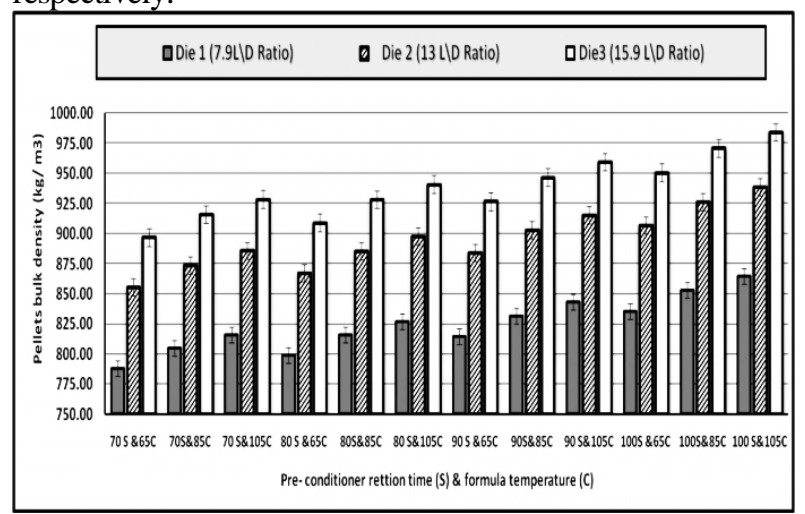

Fig. 13. The effect of die $L / D$ ratio, formula retention time in pre-conditioner and formula temperature on pellets bulk density

The slight increase in pellets bulk density by increasing formula retention time in pre-conditioner and formula temperature attributed to the increase in formulation steam absorption and that lead to increase the formula homogeneity that rise to increase the formula compact in die holes then increase the pellets mass in constant volume.

\section{5- Aquatic feed pellets durability}

Pellets durability is measurement usedto determine the solidity of the pellets during storage, handling and transportation. Data in Fig (14) showed the effect of die L/D ratio, formula retention time in pre-conditioner and formula temperature on pellets durability. Results indicated that increasing die L/D ratio from 7.9 to 13 and 15.9 increased the produced aquatic feed pellets durability as average at all formula retention times in pre-conditioner and formula temperature from 84.97 to 92.27 and $93.85 \%$ respectively. The increase in pellets durability by increasing die L/D ratio could be due to the increase in pellets solidity by increasing die holes holding time that lead to decrease the interfaces volume and cracks between formula granules.

When analyzing the effect of formula retention time in pre-conditioner results on pellets durability, Fig (14) showed increasing the formula retention time in pre-conditioner at all formula temperatures from 70 to 100 s increased positively the durability from $80.07,86.96$ and $88.44 \%$ to $87.86,95.41$ and $97.04 \%$ using dies L/D ratio of 7.9, 13 and 15.9 respectively. The increase in pellets durability could be due to the increase of retention time make the steam reaches the granules center of the formula ingredients and makes the granules more cohesively that led to improve the pellets compressing process and reduce the pellets cracks and reduce the broken pellets percentage during durability testing.

Given to the effect of formula temperature on pellets durability results showed in Fig (14) appeared that increasing the formula temperature from 65 to 85 Co increased the pellets durability as average for all formula retention times in pre-conditioner from $84.39,91.65$ and $93.22 \%$ to 85.57 , 92.93 and $94.52 \%$, while increase the formula temperature up to $105 \mathrm{Co}$ decreased the pellets durability to $84.93,92.24$ and 93.81\% using dies L/D ratio of 7.9, 13 and 15.9 respectively. The obtained increase in pellets durability by increasing the 
formula temperature from 65 to $85 \mathrm{Co}$ can be explained it is due to more cooking for formula lead to produce polished surface texture pellets able to resist the shocks in durability box. Meanwhile, the weak decrease in pellets durability by increasing the formula temperature up to $105 \mathrm{Co}$ could be due to at this temperature the steam is not completely dry and increases the formula moisture content that lead to appearance cracks in pellets after cooling and sifting operations lead to collapse the pellets after durability testing.

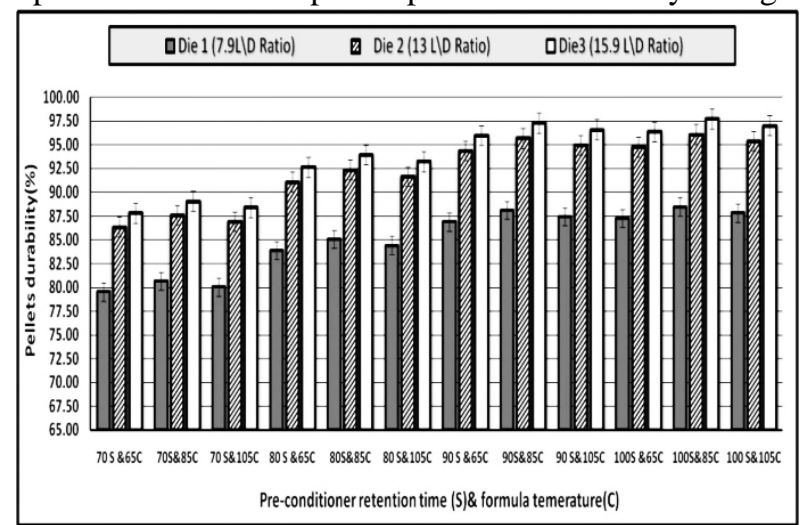

Fig. 14. The effect of die $L / D$ ratio, formula retention time in pre-conditioner and formula temperature on pellets durability.

6- Aquatic feed pellets water stability.

One of the most important specifications that fish farmers are looking for in the used aquatic feed pellets is the pellets water stability. The fast breakdown of pellets in the water leads to a suffering huge loss in aquaculture farms. Data in Fig (15) showed that increasing dies L/D ratio from 7.9 to 13 and 15.9 increased pellets water stability at all formula retention times in pre-conditioner and formula temperature from53.34, to 66.57 and $68.48 \%$ and from 17.44 to 31.91 and $44.18 \%$ after 30 and 60 min respectively. The increase in pellets water stability by increasing dies L/D ratio could be due to the increase in pellets bulk density and that lead to reduce the interfaces between the granules, it is known that the pellets will be collapsed when the water fills the spaces between the granules of the pellets.

From previous data in Fig(15) is clear to know that increasing the formula retention time in pre-conditioner from 70 to 100 s increased positively the pellets water stability as average at all formula temperature from 49.24,61.45 and $63.21 \%$ to $56.39,70.39$ and $72.40 \%$ after 30 min sinking in water and from 14.92, 27.29 and $37.79 \%$ to $21.21,38.81$ and $53.74 \%$ after 60 min sinking in water using dies L/D ratio of 7.9, 13 and 15.9,respectively.The increase in pellet water stabilty by increasing the formula retention time in preconditioner from 70 to 100 s could be due to the increase in formula steam absorption and that lead to improove the pelleting process and reduce the interfaces volume between granules.

On ather hand, increasing formula temperature from 65 to $85 \mathrm{C}^{\circ}$ increased the pellets water stability at all formula retention time in pre-conditioner from52.21, 65.17 and $67.03 \%$ to $54.60,68.15$ and $70.10 \%$ after $30 \mathrm{~min}$ sinking in water, and from $17.07,31.24$ and $43.25 \%$ to $17.85,32.66$ and $45.23 \%$ after 60 min sinking in water, using dies L/D ratio of $7.9,13$ and 15.9 ,respectively. The increase in pellets water stability by increasing the formula temperature could be due to the high limited formula temperature lead to improve the formula cooking and the formula will facing another increase in presure and temperature through pelleting process, all that occurse to genarate a low degree of starch gelatinization for the pellets and that makes the water penetrate into the interfaces between the granules so difficult.

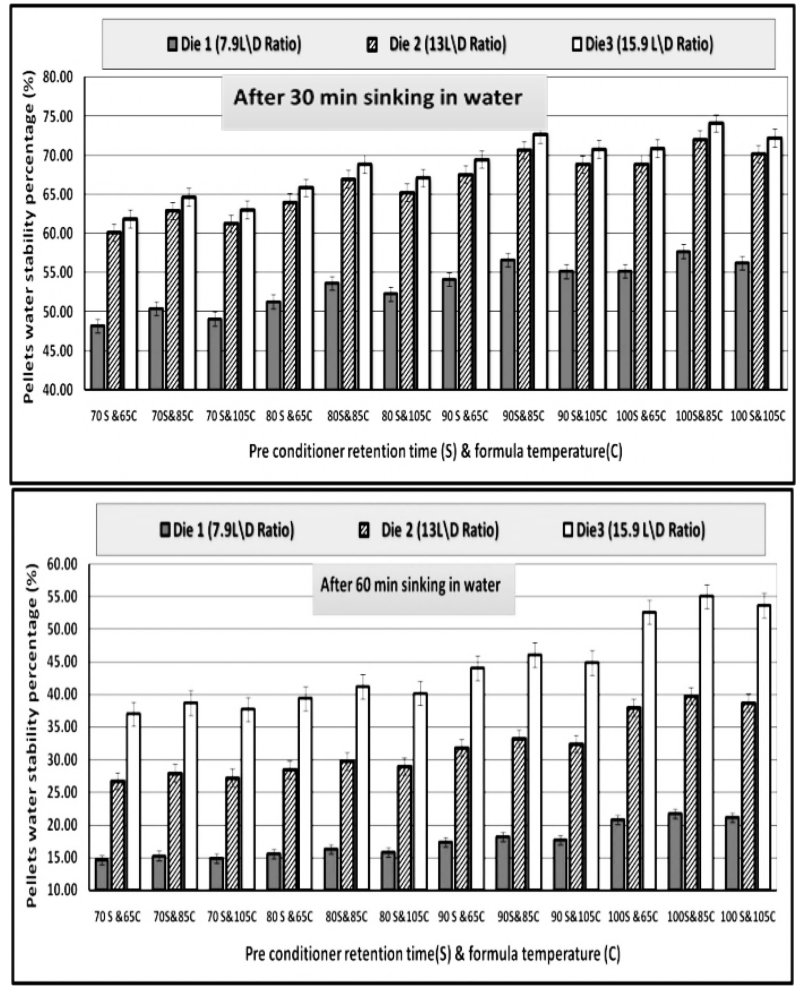

Fig. 15. The effect of die $\mathrm{L} / \mathrm{D}$ ratio, formula retention time in pre-conditioner and formula temperature on pellets water stability after sinking in water $\mathbf{3 0}$ and 60 minutes.

While increasing the formula temperature up to $105 \mathrm{C}^{\circ}$ resulted unsignfecant decreased in the pellets water stability to $53.20,66.40$ and $68.30 \%$ after 30 min sinking in water and to $17.40,31.83$ and $44.07 \%$ after 60 min sinking in water using dies L/D ratio of 7.9, 13 and 15.9, respectively.The wake decrease in pellets water stability by increasing the formula temperature up to $105 \mathrm{C}^{\circ}$ could be due to the increase in formula moisture content at this temperature, as we know increasing steam temprature need increase of the bolier steam out put or production , steam flow through what we called traps to remove moisture from steam to produce the roasted steam (dry steam) before inject it in the pellet mill pre-conditioner. Increase the steam out put lead to produce wet steam, after drying and cooling the produced pellets and take of the moisture, the pellets becomes crisp and quickly collapses in the water.

\section{CONCLUSION}

From obtained data after study the design specification and dies holes dimensions of three of common dies most used to produce aquatic feed pellets has diameter of $3.5 \mathrm{~mm}$, the recommended die specification were die total thickness and effective length of $45.5 \mathrm{~mm}$, and die L/D ratio of $1: 13$ with die entry diameter of $4.25 \mathrm{~mm}$ without relief, and optimum pre conditioner processing were 90 s retention time, and $85 \mathrm{C}^{\circ}$ formula temperature, the obtained results of this parameters were $7.553 \mathrm{Mg} / \mathrm{h}$ pellet mill production rate and $7.277 \mathrm{Mg} / \mathrm{h}$ final production rate after cooling and sifting by decrease in productivity of $3.97 \%, 137$ A motor current , $9.36 \mathrm{~kW} . \mathrm{h} / \mathrm{Mg}$ energy requirement of pellet mill, $101.12 \mathrm{C}^{\mathrm{o}}$ 
operating die temperature in the range of safe die temperature. The measured quality of produced aquatic feed pellets were $903.20 \mathrm{~kg} / \mathrm{m}^{3}$ pellets bulk density, $95.69 \%$ pellets durability, $70.67 \%$ and $33.24 \%$ pellets water stability after 30 and 60 minutes sinking in water. The study recommended use this die specification with any pellet mill capacity with change in die eternal diameter.

\section{REFERENCES}

AACC, (2000). Approved Methods of the American Association of Cereal Chemists. Methods 38-12 and 46-13, 10th ed. American Association of Cereal Chemists, St Paul (MN).

ASABE, (2007). Cubes, Pellets, and Crumbles-definitions and Methods for Determining Density, Durability, and Moisture Content. American Society of Agricultural and Biological Engineers (ASABE), pp. 2007.

FAO, (1980). Fish Feed Technology, Training Course in Fish Feed Technology, College of Fisheries. University of Washington, WA, U.S.A, United Nations Development.

FAO, (2017).Aquaculture Regional Reviews. FAO Fisheries and Aquaculture Department [Online], Rome (Updated 8 February 2017).

Joshua J.; T. Aaron; M. Tyler and M. Michael (2016) Densification of biomass using a pilot scale flat ring roller pellet mill. Fuel Processing Technology 148, 43-49

Kamarudin, M. S.; C.R. de Cruz; C.R.Saad; N.Romano and E. Ramezani-Fard (2018). Effects of extruder die head temperature and pre-gelatinized taro and broken rice flour level on physical properties of floating fish pellets. Anim. Feed Sci. Technol. 236, 122-130.

Larsson S.H. and M. Rudolfsson (2012). Temperature control in energy grass pellet production effects on process stability and pellet quality, Applied Energy 97, 24-29.

Larsson S. H.; M. Rudolfsson; M.Thyrel; H.Örberg; G.Kalén and M. Wallin (2012) Temperature controlled feed layer formation in biofuel pellet production. Fuel 2012; 94:81-5.

Mani, S.; L.G. Tabil and S. Sokhansanj (2006) Effects of compressive force, particle size and moisture content on mechanical properties of biomass pellets from grasses, Biomass Bioenergy 30 (7) 648-65
Magnus, R.; H. Sylvia; T. Larsson and A. Lestander (2017 a). New tool for improved control of sub-process interactions in rotating ring die pelletizing of torrefied biomass. Applied Energy 190 (2017) 835-840

Magnus, R.; B. Eleonora; P.Linda ; N. Anders and A. Lestander (2017 b) Combined effects of torrefaction and pelletization parameters on the quality of pellets produced from torrefied biomass. Applied Energy $191,414-424$

NRC, (2011).Nutrient Requirements of Fish and Shrimp. National Academies Press, Washington, DC, USA, pp. 301-324

Reed, T.B.; G.Trezek and L. Diaz (1980). Biomass densification energy requirements. In: Jones, J.L., Radding, S.B. (Eds.), Thermal Conversion of Solid Wastes and Biomass. , pp. 169-177, ACS Symposium Series 130, Washington, DC.

Rout, R.K. and S. Bandyopadhyay (1999). A comparative study of shrimp feed pellets processed through cooking extruder and meat mincer. Aquac. Eng. 19, 71-79.

Thek, G. and I. Obernberger (2004). Wood pellet production costs under Austrian and in comparison to Swedish framework conditions, Biomass and Bioenergy 27, 671-693.

Tumuluru,J.S.; S. Sokhansanj; C.J. Lim; T. Bi, A. Lau; S. Melin ; T. Sowlati and E. Oveisi (2010). Quality of wood pellets producedin British Columbia for export. Appl. Eng. Agric. 26, 1013-1020.

Tumuluru, J.S.(2015). High moisture corn stover pelleting in a flat die pellet mill fitted with a $6 \mathrm{~mm}$ die: physical properties and specific energy consumption. Energy Sci. Eng. 3, 327-341.

Tumuluru J.S. (2016) Specific energy consumption and quality of wood pellets produced using high-moisture lodgepolepine grind in a flat die pellet mill. Chemical engineering research and design 110, 82-97

Tumuluru, J.S.; C.C. Conner and A. N.Hoover (2016). Method to produce durable pellets at lower energy consumption using high moisture corn stover and a corn starch binder in a flat die pellet mill. J. Vis. Exp., e54092.

\footnotetext{
تأثير نسبة الطول الفعال الي قطر الثقب في الداي الحلقي وعوامل التشغيل لوحدة التهيئة علي اداء المكبس الحلقي وجودة اعلاف الأسماك الغاطنة الفئة أسنامة قدور قسم الهنسة الزراعية ـ قسم العلوم الهنسية ـ كلية الثروة السمكية ـ جامعة السويس

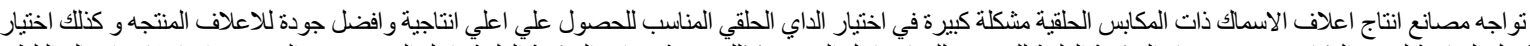

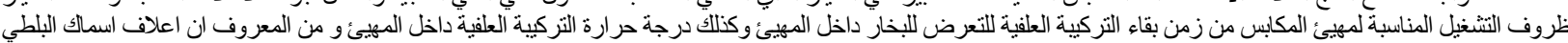

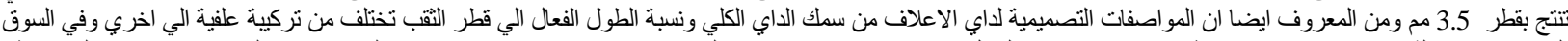

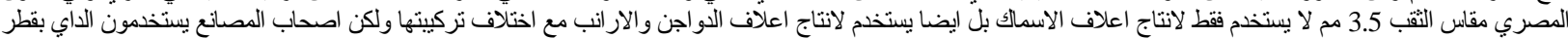

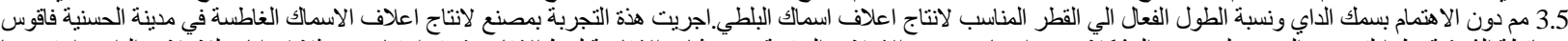

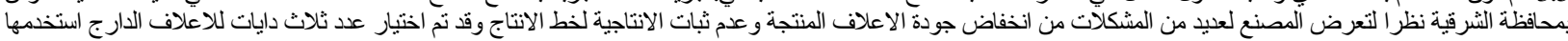

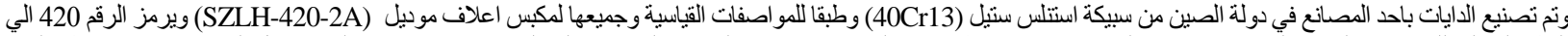

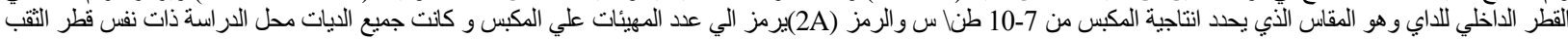

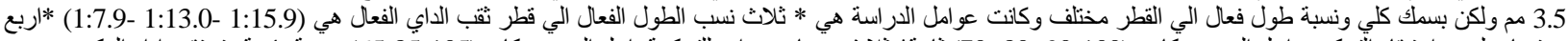

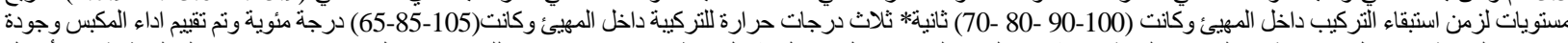

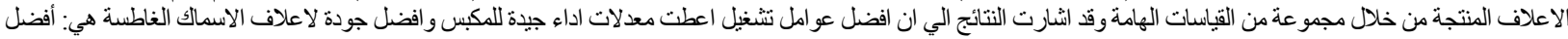

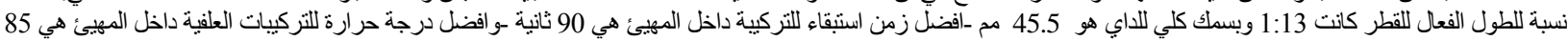

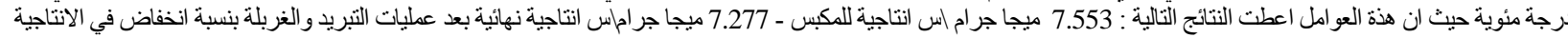

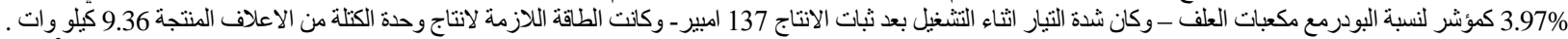

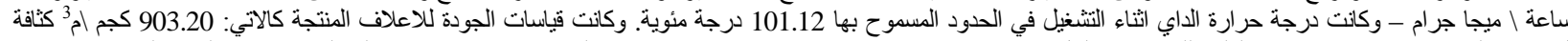

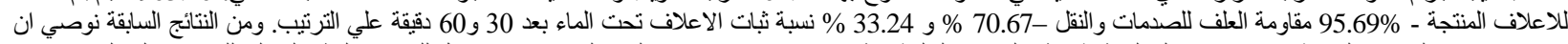

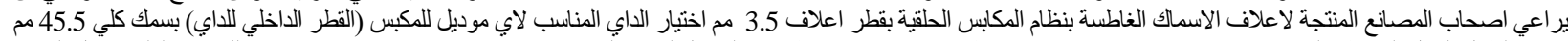

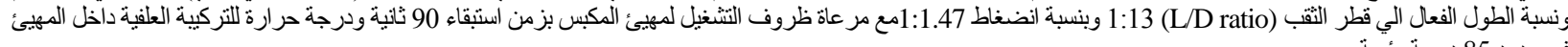
في حدود 85 درجة مئوية
} 